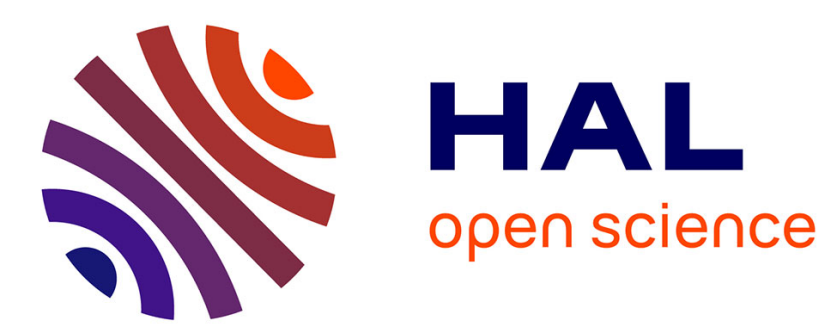

\title{
Towards a Constructional Approach of L2 Morphological Processing
}

\author{
Hélène Giraudo, Serena Dal Maso
}

\section{To cite this version:}

Hélène Giraudo, Serena Dal Maso. Towards a Constructional Approach of L2 Morphological Processing. Geert Booij. The construction of words, Advances in Construction Morphology, Springer International Publishing, pp.603-622, 2018, 10.1007/978-3-319-74394-3_21 . hal-02434647

\section{HAL Id: hal-02434647 \\ https://hal.science/hal-02434647}

Submitted on 3 Jan 2022

HAL is a multi-disciplinary open access archive for the deposit and dissemination of scientific research documents, whether they are published or not. The documents may come from teaching and research institutions in France or abroad, or from public or private research centers.
L'archive ouverte pluridisciplinaire HAL, est destinée au dépôt et à la diffusion de documents scientifiques de niveau recherche, publiés ou non, émanant des établissements d'enseignement et de recherche français ou étrangers, des laboratoires publics ou privés. 


\title{
Towards a Constructional Approach of L2 Morphological Processing
}

\author{
Hélène Giraudo and Serena Dal Maso
}

\begin{abstract}
Following Silva \& Clahsen seminal work, psycholinguistic research on L2 morphological processing has mainly adopted a morpheme-based, decompositional dual route approach suggesting that L2 learners have a limited access to morphological representation during processing and consequently rely more on lexical storage (Clahsen H, Felser C, Neubauer K, Sato M, Silva R, Lang Learn 60:21-43, 2010; Clahsen and Felser, 2017). Therefore, experimental research, which largely used the masked priming paradigm, mainly focused on the distinction between storage and computation as two alternative, mutually exclusive and competing mechanisms. In this paper, we claim that a word-based approach, which considers morphology in terms of constructional schemas, allows us to overcome the rule vs. list fallacy and therefore reshapes the dichotomy between L1 and L2 processing mechanisms. Although a consistent proposal is still out of reach, given that data on L2 processing are limited, we will discuss the advantages of a model which jointly considers formal and semantic similarities, as well as paradigmatic proprieties.
\end{abstract}

Keywords Second language acquisition · L1-L2 morphological processing · Masked priming

\section{Introduction}

The first psycholinguistic studies on second language acquisition (SLA) claimed that the processing of morphologically complex words operates differently in native (L1) and non-native speakers (L2) (see for a review Clahsen et al. 2010). According to this view, adult second language learners, even at the highest levels of L2

H. Giraudo (两)

CLLE, Université de Toulouse, CNRS, Toulouse, France

S. Dal Maso

Department 'Culture e Civiltà', University of Verona, Verona, Italy

(C) Springer International Publishing AG, part of Springer Nature 2018

G. Booij (ed.), The Construction of Words, Studies in Morphology 4, https://doi.org/10.1007/978-3-319-74394-3_21 
proficiency, because of their limited access to the procedural memory system, would be less efficient in parsing complex words in their morphological constituents and consequently in computing the morphological structure of complex words. On the contrary, they would rely more than native speakers on lexical storage during word recognition. As we will discuss, such an interpretation is deeply rooted in a dual route 'decompositional' psycholinguistic model of processing and lexical access and clearly refers to morpheme-based approaches to morphology. A growing body of results, however, cannot be accounted for within this model and suggests an alternative picture of L2 processing (Feldman et al. 2010; Voga et al. 2014; Dal Maso and Giraudo 2014; Coughlin and Tremblay 2015) which strongly calls into question the proposed strict opposition between native and non-native processing and, more generally, the decompositional perspective on which it is based. In the present contribution, we will review highly debated issues in this still relatively young domain (i.e., the dichotomy between inflection and derivation, the dichotomy between regularly and irregularly inflected forms, frequency and series effects), and we will suggest that a word-based approach which considers morphology in terms of constructional schemas, as in Construction Morphology (CxM), is better suited to account for L2 processing mechanisms. Although a consistent proposal is still out of reach, given that data on L2 processing are limited, we aim at discussing the advantages of a model which jointly considers formal and semantic similarities, as well as paradigmatic proprieties.

\section{Masked Priming Research on Morphological Processing}

In the last 20 years of psycholinguistic research, the nature of connections among morphologically connected word in the mental lexicon has been investigated mostly by means of the masked priming technique, generally associated with a lexical decision task (LDT). Basically, in masked priming (Forster and Davis 1984), a prime word, which is virtually invisible to the participants because of its brief presentation times $(<60 \mathrm{~ms})$, precedes the presentation of a target word on which participants are asked to perform a lexical decision (i.e., decide as quickly and accurately as possible if the item is a word or not) while their recognition latencies are recorded. The masked priming experimental technique has been considered as particularly suited to explore the automatic and unconscious processes occurring in the speakers' minds during word processing because, since participants are not aware of the presentation of the first stimulus, they cannot develop any predictive response strategy. Therefore, any facilitation observed in masked priming experiments cannot be considered to derive from a conscious appreciation of the relation between the prime and the target and a consequent metalinguistic reasoning (Forster 1998). As for the processing mechanisms, this technique provides the possibility to explore the automatic transfer of facilitation or inhibition from the prime to the target in different priming conditions. Morphological effects are usually examined by comparing the facilitation induced by a prime on the recognition of a morphologically related target word 
(e.g., singer/SING) with the effect of an unrelated prime on the recognition of the same target (e.g., banker/SING). Recently, morphological effects have been more frequently observed in relation to an orthographic condition (e.g. sinner/SING) in order to exclude the existence of any facilitation induced by the formal/orthographic overlap within the prime-target pair.

From the seminal repetition priming study conducted by Stanners et al. (1979) to the most recent investigations combining masked priming with techniques which observe brain activity (e.g., Morris et al. 2013), morphological priming effects have been extensively studied and have systematically revealed strong facilitation effects in a large number of languages with different morphological features; German and Dutch: Drews and Zwitserlood (1995); French: Grainger and Dal Maso (2016a, b); Arabic: Boudelaa and Marslen-Wilson (2011); Chinese: Ding et al. (2004); Japanese: Clahsen and Ikemoto (2012); Korean: Kim et al. (2015). The fact that experimental results exhibiting morphological effects (where a morphologically related prime facilitates the recognition latency of its base presented as the target) differ significantly from formal and semantic relationships (where a mere formal and/or a mere semantically related prime is actually used as a base of comparison), led the authors to conclude that independent morphological representations were coded within the mental lexicon in a similar way as orthographic, phonological, and semantic representations. In the present paper, therefore, we will mainly refer to results obtained within this experimental paradigm, in order to deal with comparable data, although we may occasionally mention outcomes obtained using other techniques (namely, overt or cross-modal priming).

Although the role of morphology is quite unanimously acknowledged, a lively debate has developed on its interpretation in terms of models of lexical access and processing. Specifically, theoretical positions crucially differ as for the locus of morphological representations within the lexicon (i.e., pre-lexical or lexical) and therefore its functioning mechanisms (parsing vs lexical organization). The pre-lexical, decompositional, morpheme-based account, claims that in processing morphologically complex stimuli (e.g., singer), an obligatory morphemic parsing takes place and word representations are accessed through their morphemic components (e.g., sing and -er) (Taft and Forster 1975; Taft 1994; Marslen-Wilson and Tyler 1997; Rastle and Davis 2008). The supra-lexical approach, on the other hand, proposes a crucially different perspective (Giraudo and Grainger 2000, 2001; Giraudo and Voga 2007, 2014): morphologically structured stimuli are accessed through their whole-word forms (i.e., lexical representations), which in turn contact the morphological units they are made up of. In this model, these supra-lexical units are supposed to be abstract nodes that stand at the interface between wholeword forms (coded at the lexical level) and meaning representations (coded at the semantic level) and organize words in paradigms i.e., morphological families and 
series $^{1}$ (Giraudo and Grainger 2000, 2001; Pastizzo and Feldman 2002; Giraudo and Voga 2007, 2014).

In SLA, the domain of empirical investigations of morphological processing is relatively young and although experimental research that focuses on the cognitive on-line processes using the masked priming paradigm has been developing only recently, and the available results are still quantitatively limited. ${ }^{2}$ Moreover, because of inherent difficulties of experimentation with non-native speakers, and because of methodological discrepancies, the studies so far conducted have resulted in rather controversial evidences as to the efficiency and nature of morphological processing mechanisms in L2 (compared to L1), so that the question whether morphology plays a role at all is still an open one. In SLA research, the discussion aims at determining whether L1 and L2 morphological processing mechanisms are substantially different or that the observed differences can be accounted for in terms of different proficiencies in the two linguistic systems. Ultimately, the question is to verify whether L1 and L2 morphological processing are qualitatively or quantitatively different. Thus, research on morphological processing contributes to a more general debate on L2 online functioning, in which two main positions are confronted. On the one hand, some researchers maintain that L1 and L2 have the same processing system and that any difference emerged in empirical studies can be accounted in terms of slower, i.e. more memory-demanding cognitive processes (Ellis 2005; Perani and Abutalebi 2005; McDonald 2006; Abutalebi and Green 2008; MacWhinney 2011) and possibly affected by L1 transfer (Sabourin and Haverkort 2003; Portin et al. 2007; Chen et al. 2007). On the other hand, a different position claims that the mechanisms underlying native and non-native processing are substantially different (Silva and Clahsen 2008; Neubauer and Clahsen 2009; Kirkici and Clahsen 2013; Jacob et al. 2013; Heyer and Clahsen 2015; Bosch and Clahsen 2016). This latter view is mainly based on the declarative/procedural model (DP) proposed by Ullman (2004), which distinguishes between a computational system involved in the processing of the combinatorial rules of language (i.e., computation) and a memory system which is responsible for the storage of memorized words. ${ }^{3}$ On the basis of the DP model, some researchers have interpreted the differences between native and non-native performances as an evidence of the fact that L2 learners rely considerably more on the declarative system as their

\footnotetext{
${ }^{1}$ There also exists 'hybrid', dual-route models (i.e., the AAM, Augmented Addressed Morphology developed by Burani and Caramazza (1987) and Caramazza et al. (1988), and the Morphological Race Model proposed by Schreuder and Baayen (1995) which posits two different ways of processing complex words, the choice of which crucially depends on their surface frequency: highly frequent words will be accessed directly through their whole form, while less frequent ones will be parsed and accessed via their constituents.

${ }^{2}$ In SLA, the cross-language priming is also used, mainly in order to investigate the lexical rather than the morphological processing (Potter et al. 1984; Kroll and Stewart 1994). On cross-language priming in morphological research, see Voga (2005), Basnight-Brown et al. (2007), on auditory priming Gor and Cook (2010); Gor and Jackson (2013).

${ }^{3}$ However, see Ullman (2006) on Clahsen's interpretation of the DP model.
} 
procedural system is 'impaired' or not (completely) available. As far as morphology is concerned, this would imply that morphological information is not encoded in the L2 mental lexicon or that its functioning is not as efficient as for native speakers. Such a claim is a coherent extension of the 'shallow-structure hypothesis (SSH)' formulated for L2 processing of syntax and morphosyntax (Clahsen and Felser (2006); see Clahsen and Felser (2017) for an up-to-date account and revision of $\mathrm{SSH})$. Such a hypothesis suggests that in L2 learners, syntactic parsing is not supported to the extent it is in L1 speakers and that consequently, L2 sentence processing is based on lexical semantic cues rather than on syntactic cues.

So, as the storage vs computation opposition seems to be a crucial point in order to grasp the L1 and L2 differences, in what follows, we will discuss the domains traditionally exploited to disentangle the two mechanisms in native processing, i.e., inflection and derivation, regular and irregular inflection, and frequency effects. We will suggest that assuming a 'constructional' perspective on L2 processing allows us to overcome the traditional storage $v s$ computational dichotomy and consequently the well-known 'rule/list fallacy' (Langacker 1987), according to which linguistic constructs are either created by rules or listed in the lexicon. We claim that the fact that a complex word might be 'listed', i.e., memorized in the mental lexicon, does not necessarily exclude that it is at the same time linked to a 'rule', i.e., a regular pattern, such as a morphological schema. Morphological schemas have the function of encoding the predictable properties of existing complex words and by doing so, to give structure to the lexicon as they group complex words in families (i.e., words with the same base) and series (i.e., words with the same affix) (Booij 2010: 4). Morphological schemas also indicate how new words can be coined but, as psycholinguistic research has not considered speakers 'creative competence', this specific function of morphological schemas will not be discussed here.

\section{Inflection vs Derivation}

\subsection{Storage and Computation}

The opposition between inflection and derivation is one of the most debated issues in the research on L2 processing, and has been considered by some scholars as a critical domain to capture the specificity of non-native processing mechanisms. Starting from the observation that the facilitation effect typically obtained with inflected primes in L1 does not systematically emerge with L2 learners, a specific 'impairment' of the computational component (compared to the storage component) has been hypothesized for L2 processing. However, as detailed below, both the results obtained so far and the interpretations proposed are not completely consistent, especially as far as inflection is concerned, so that implications in terms of theoretical models of L2 processing are still tentative. The lack of consensus on the efficiency of both inflected and derived primes is due to both theoretical 
and pragmatic factors. As for the latter, in the still relatively young domain of L2 processing research, only a limited number of studies have systematically considered both inflection and derivation (e.g., Diependaele et al. 2011; Dal Maso and Giraudo 2014 only focus on derivation) and even when both systems have been investigated, they have been rarely directly compared (at least until recent experiments by Jacob et al. (2017) and Dal Maso and Giraudo (submitted)). On the other hand, divergent interpretations of results reflect the different theoretical positions taken with respect to the demarcation between inflection and derivation, which is a classical issue for morphological theories. A strong and relatively clearcut dichotomy between the two kinds of processes is advocated by the 'split morphology' hypothesis (Anderson 1982; Perlmutter 1988). This view claims two separated components of the grammar: derivation, located in a pre-syntactic morphological component, which functions to enrich the lexicon, and inflection, located in a post-syntactic component, which only spells out the correct inflectional form of the word depending on its position in the syntactic structure. An alternative view posits only one morphological component and a sort of inflection - derivation continuиm, articulated according to the mapping of relationships between different word forms through associatively linked orthographic, phonological and semantic codes. This view, thus, implies a gradient, rather than a simple inflection $v s$ derivation dichotomy (Bybee 1985; Dressler 1989; Plank 1994; Booij 1996).

Crucially, in CM both inflection and derivation are represented as constructions, which exhibit holistic properties (both formal and semantic ones) that do not derive only from word- internal constituents, but rather from their paradigmatic organization. Taking such a word-based network perspective, CM is thus less concerned with the internal 'building blocks' of morphologically complex forms, but rather in their organizations in morphological families (words that share the same base) and morphological series (words that share the same affixation patterns, see Booij 2010: 32). CM has been proven to be particularly effective to account for a certain number of relatively common phenomena in inflectional systems, which are highly problematic for morpheme-based approaches and derive from the fact that in no language there is a one-to-one correspondence between the building blocks of inflected words and their morpho-semantic properties. Morpheme-based approaches described such cases of morpho-syntactic and morpho-semantic opacity in terms of notions like cumulative exponence, extended exponence, stem allomorphy, inflectional classes, thematic vowels, syncretism, suppletion, etc. From a constructionist point of view, on the other hand, it is the schema as whole, which evokes a specific set of morpho-syntactic and morpho-semantic properties, and thus the set of properties is a holistic property of the inflectional construction. That is, inflectional phenomena provide direct evidence for the idea that morphologically complex words should be seen as constructions with holistic properties (Booij 2010: 22).

Experimental research on native speakers has investigated the psychological reality of linguistic distinctions between inflected and derived words, without solving 
the theoretical diverging positions, which are replicated in essentially two families of psycholinguistic models (see Diependaele et al. 2012 for a detailed discussion of these psycholinguistic models). Basically, morpheme-based approaches gave rise to dual mechanism accounts which mainly argue that the linguistic distinction between inflection and derivation is reflected in the manner in which morphologically complex words are represented and processed (Stanners et al. 1979; Taft 1985, 1994; Henderson 1985; Pinker 1991; Pinker and Prince 1988; Clahsen et al. 2003). Stanners et al. (1979), for instance, hold that derivational forms are explicitly stored in the mental lexicon, but regularly inflected forms are not. Inflected forms, by virtue of their paradigmatic nature and semantic predictability are processed by applying rule-governed computations to the representations of their constituent morphemes. In contrast, given the semantic unpredictability of derived forms, rule-governed computation would be exceptionally costly and error-prone; consequently, the processing of derived words would rely on stored whole word representations. According to this view, the processing of inflected and derived forms relies on two qualitatively distinct mechanisms: rule-governed computation for inflected forms and lexical look-up for derived words. Stanners et al. (1979) seem to provide empirical results supporting the view according to which inflection and derivation are represented and processed differently. They found that lexical decisions were facilitated when base-form targets were preceded by inflected primes (e.g., pours/POUR) and that this effect was equal in magnitude to identity priming (e.g., pour/POUR). In contrast, the priming effect from suffixed derived words (e.g., appearance/APPEAR) although statistically significant, was smaller than the identity priming effect.

Network and connectionists models, and of course CxM, on the other hand, are generally compatible with associative single-mechanism models which claim that all inflected words are stored and processed within a single associative system using distributed representations (Fowler et al. 1985; Sereno and Jongman 1997; Gonnerman et al. 2007). Under this perspective, connections across words would not be determined by the nature of the process at their origin, but would rather be a function of the degree of semantic and phonological /orthographic overlapping, the frequency of the whole form, the size, salience and consistency of morphological families and series they belong to, etc. Results of direct comparisons between priming effects induced by inflected and derived forms seem to confirm this line of interpretation as no substantial difference emerged in the two conditions. Raveh and Rueckl (2000) manipulated inflected and derived primes paired with the same target word (e.g., believed/BELIEVE and believer/BELIEVE); moreover, both kinds of primes equated in terms of their orthographic similarity to the targets. With this experimental design, equivalent effects for inflected and derived primes were obtained across these experiments. Thus, for Raveh and Rueckl (2000) there is no support for the claim that different classes of morphologically complex words are processed in different ways: "our results indicate that the syntactic and semantic differences between inflections and derivations are not sufficient to produce a 
difference in the manner in which these classes of words are processed. At least in the case of visual word recognition, lexical processes do not appear to be organized around morphological categories per se. If further research shows that in some circumstances (e.g., with high frequency primes) inflections and derivations do give rise to priming effects of different magnitudes, the account of those results cannot be in terms of linguistic categories. Instead, a more fine-graded analysis couched in terms of the interaction of a variety of statistical and structural variables will be required" (Raveh and Rueckl 2000: 116).

Before turning to results of studies on L2 processing, an important point need to be discussed, namely the 'parsing' mechanism which is generally associated with the morphological effect, and the 'affix stripping mechanism' which is advocated to be at the base of all morphological effects. In fact, although both dual models and holistic ones acknowledge a role for morphology during word processing and access, they crucially differ with respect to the locus of morphological representation within the lexicon (i.e., pre- or post-lexical) and therefore its functioning mechanisms (parsing vs lexical organization). According to morpheme-based accounts, the processing of a morphologically complex stimulus (e.g., walked, walker) implies a pre-lexical obligatory morphemic parsing, and word representations are accessed through their morphemic components (e.g., walk and -ed/ -er) (Taft and Forster 1975; Taft 1994; Marslen-Wilson and Tyler 1997; Rastle and Davis 2008). The so-called 'full priming'4 effect found with regular inflected forms would indicate that these forms are recognized by first decomposing the whole-word into its morphological constituents and then accessing the representation of the base. Hence, identical and inflected primes give rise to equivalent magnitudes of priming because in both cases, the same access unit is activated by the prime and the target. In contrast, the 'partial priming' or 'reduced priming' (relative to the identity condition) found for irregular inflections would indicate that these forms are not parsed into their constituent morphemes and are instead recognized by directly accessing their whole-word representations in the lexicon. Holistic models (i.e., the supra-lexical approach) propose a crucially different perspective: because all morphologically structured stimuli are accessed through their whole-word forms, no difference is expected between inflections and derivations or between regulars and irregulars. Two morphologically related words prime each other thanks to the fact that their lexical representations are indirectly linked via supralexical representations that cluster together words from the same morphological family and from the same series. Masked priming effects obtained with pseudo-derived words like corner-corn (see Rastle and Davis 2008 who reviewed the systematic positive priming effects found for this type of primetarget pairs) are explained in this model in terms of surface formal effects (see Giraudo and Dal Maso 2016b for a discussion).

${ }^{4}$ Morphological and identity primes produce the same amount of priming on target recognition. 


\subsection{L1 Vs L2: Different Patterns of Morphological Facilitation?}

Starting from the seminal work by Silva and Clahsen (2008) on L2 English, priming effects with derived primes emerged regularly in L2 Turkish (Kirkici and Clahsen 2013), in L2 Italian (Dal Maso and Giraudo 2014) and in L2 English (Heyer and Clahsen 2015). In all these studies, a derived prime triggers facilitation in the recognition of the target relative to an unrelated condition and, in some cases, relative to an orthographic/formal condition as well. In fact, the only study which failed to observe a morphological facilitation with derived primes is the one conducted by Clahsen and Neubauer (2010), in which nominalizations in -ung in L2 German were considered (e.g., Bezahlung 'payment' did not prime BEZAHLEN 'pay').

A more complex experimental design has been used by Diependaele et al. (2011) who manipulated three types of prime-target pairs with different degrees of formal overlapping and semantic transparency: transparent suffixed primes (e.g., viewer NIEW), opaque or pseudo-suffixed primes (e.g., corner/CORN), and form control primes (e.g., freeze/FREE). This experimental design aimed at assessing on the one hand, the effect of semantic transparency between prime and target and, on the other, the role of formal, orthographic factors. The goal thus was to verify the hypothesis of a stronger reliance on orthographic representations and on word forms in non-native speakers' processing (as proposed by Feldman et al. 2010, but on this point see $\S 4$ ). The masked priming experiment conducted with two groups of late bilinguals (i.e., Spanish-English and Dutch-English) revealed a graded pattern of facilitation across conditions, i.e., priming effects were largest in the transparent condition, smallest in the control formal condition and intermediate in the opaque condition. Taken together, these results indicate that the priming effects induced by transparent derived primes are stable (at least relative to the unrelated condition) and quite univocally observed.

A quite different and more complex picture emerges, on the contrary, for inflection. Basically, Clahsen and collaborators failed to obtain morphological effects induced by inflected primes (Silva and Clahsen 2008 in L2 English; Neubauer and Clahsen (2009) in L2 German; Kirkici and Clahsen (2013) in L2 Turkish), whereas Feldman et al. (2010), Voga et al. (2014) and Coughlin and Tremblay (2015) consistently found significant priming effects triggered by inflected forms in L2 English.

The most striking L1 - L2 difference has been found with regularly inflected past tense forms: both Silva and Clahsen (2008) for L2 English (e.g., walked/WALK) and Neubauer and Clahsen (2009) for L2 German (e.g., geordnet - ORDNE 'arrange(I) arrange') obtained no significant priming effect for L2 speakers, as opposed to L1 speakers, whose reaction times were significantly faster in the morphological condition with respect to the control baseline. Starting from these initial findings, and considering the 'partial' or even absent priming effect with derived forms, it was proposed that L2 morphological processing is overall 'impaired' (and regular 
inflection more clearly) or not operative during the early stages of word recognition. It should be kept in mind that in Clahsen and colleagues' works, morphological priming implies the decomposition of complex forms in morphological constituents and lexical access through the isolated stem. Accordingly, what is impaired in L2 learners is the ability to decompose the words into stem and inflectional suffix because of a L2 learners' limitation of the procedural memory system and an overreliance on lexical storage.

This initial hypothesis was later confirmed by Kirkici and Clahsen (2013) who focused on regularly inflected forms (e.g., the Aorist verb form) and on deadjectival nominalizations in L2 Turkish. Again, no significant morphological effects were yielded by inflected primes, whereas significant priming effects were induced by derivationally related primes. ${ }^{5}$ Kirkici and Clahsen (2013) explained the diverging patterns of results for inflection and derivation by suggesting that priming for derived words would arise via the lexical route, whereas a 'lexically mediated' priming would not be possible for inflected forms. "Since regularly inflected forms do not have their own lexeme entries, morphological decomposition is the only source of masked priming effects for regular inflection. This means that during early visual word recognition in an L2, a lexeme such as [walk] is not activated by the prime/walked/because walked is not morphologically decomposed, and hence there is no priming in such cases" (Kirkici and Clahsen 2013: 786). ${ }^{6}$

Thus, the crucial difference between L1 and L2 processing would consist in the efficiency of the decomposition mechanism, as without a successful process of affix stripping there can be no access to the stem shared by inflected words and their base. The conclusion therefore is that: "advanced L2 learners' lexical representations of morphologically complex words are identical to those of L1 speakers, but (unlike in the L1) L2 processing does not make use of morphological decomposition. Consequently, masked priming effects in the L2 can only arise in cases in which prime and target words share lexical entries" (Kirkici and Clahsen 2013: 787). Therefore, in the interpretation proposed by the authors the contrast between inflection and derivation would be even more visible in L2 than in L1 data.

Such an explanation raises, however, some concerns regarding its psychological plausibility because it claims that in L2, representations of inflected forms are neither lexically nor morphologically connected, which would turn out to be the less efficient (and most costly) choice for the learners. Even if we assumed that

\footnotetext{
${ }^{5}$ Similar results were obtained by Jacob et al. (2013) with Russian learners of L2 German processing past participle forms (-t participle gestoppt-stoppe 'stopped-(I) stop; -n participles with no stem change gesalzen-salze 'salted-(I) salt'; -n participle with stem change gestohlen-stehle 'stolen-(I) steal') using, though, a cross-modal priming (e.g. auditory primes and visual targets).

6"Here we suggest that morphological decomposition is not operative during early L2 word recognition and that this causes the unusual morphological priming patterns reported for L2 learners (Kirkici and Clahsen 2013: 786).“The L2 data provided clear psycholinguistic evidence for a contrast between inflection and derivation, which was not visible from L1 data. This contrast is consistent with that posit precisely the kind of split observed in the L2 data" (Kirkici and Clahsen 2013: 787).
} 
morphological decomposition is not operative in L2 and that consequently no computation takes place, the reason why L2 learners should not lexically 'store' inflected forms (as they seem to do with derived or irregularly inflected forms) is far from being clear. Should they rely more on a declarative system rather than on a procedural one, similar effects for inflected and derived primes should be expected. At a more general level, this kind of interpretation confronts us with the extremely difficult task to disentangle morphological from lexical connections (the first one involved in inflection, the second one in derivation), on the basis of the difference between full $v s$ partial priming effects (i.e., purely quantitative/RT differences). Finally, such an interpretation does not take into account the fact that even the formal effect, which usually emerges in priming experiments (see the corner/CORN effect in Diependaele et al. 2011), fails to emerge with inflected forms.

Lack of satisfaction with this kind of interpretation led to the elaboration of alternative accounts even in a strongly decompositional approach. This is for example the case for Jacob et al. (2017), who observed the inflection-derivation opposition in L2 German, comparing the respective effects of a derived prime (e.g., Lösung 'solution') and an inflected prime (e.g., gelöst 'solved') for the same target word (e.g., lösen 'to solve'). The advantage of the experimental design used in this experiment is twofold. First, it provides the possibility to directly compare the effects yielded by inflected and derived forms, instead of comparing effects on two different sets and on different targets. Secondly, it also allows a within-group comparison, instead of a comparison of priming effects across different participant groups (one for derived and another for inflected forms), which could possibly differ in their L2 proficiency levels, age of acquisition of the L2, or other specific learning characteristics. Jacob et al. (2017) found that the L2 group showed a significant priming effect only for derived, but not for inflected primes. Moreover, this result was independent from the proficiency of the L2 speakers and from the years of experience with the L2 (number of years since the onset of German acquisition).

As for the theoretical interpretation, although Jacob et al. (2017) remain within a strictly decompositional framework, they do not explain the inflectional vs derivational opposition in 'split morphology' terms (as Kirkici and Clahsen 2013 do), i.e., by claiming that L2 learners cannot parse and compute inflected forms and that priming effects with derived forms arise through lexical mediation. They rather explain the inflected $v s$ derived opposition by considering their different semantic salience: "L2 speakers can, in principle, strip off affixes from morphologically complex words, but struggle to do so for inflected forms due to the particular properties of inflectional versus derivational affixes. One such property is that derivational affixes, unlike inflectional ones, contain semantic information. [...] the fact that derivational affixes contain meaning might allow the L2 processor to decompose a derived word in similar way as a compound. Inflectional affixes, in contrast, can be considered less salient, which potentially constitutes a problem for L2 decomposition mechanisms" (Jacob et al. 2017: 14). To our mind, this is an interesting development as the authors recognize that decomposition is not a compulsory mechanism that applies to all forms (true complex words or pseudosuffixed words, complex nonwords as stated by Rastle and Davis 2008), but that 
decomposition probability crucially depends on semantic factors (such as salience and consistency).

To sum up: in the line of reasoning developed in the first phase of the research on L2 processing, a clear-cut opposition between inflection and derivation has been advocated and interpreted as the result of learners' inability to segment inflected forms and therefore to access the stem of inflected forms. Further experiments, however, could not confirm such a strict opposition and the lack of priming effects with inflected primes.

A first challenge to Clahsen and colleagues' position comes from Voga, Anastassiadis-Symeonidis and Giraudo's (2014) replication of the Silva and Clahsen (2008) experiment with Greek learners of L2 English, which did not confirm the inflectional $v s$ derivational opposition. This study, using the same critical items as Silva and Clahsen (2008), obtained equally robust priming effects with derived (e.g., acidity/ACID; dullness/DULL) and inflected primes (e.g., walked/WALK) in L2 processing. More specifically: "Both derivational and inflectional priming were statistically equivalent to identity priming, as it is usually the case with data for native speakers (e.g. Drews and Zwitserlood 1995)" (Voga et al. 2014: 344). To which degree this discrepancy is due to methodological choices or captures a reliable effect, is a question which needs to be verified in future research. It is in fact undeniable that Silva and Clahsen's (2008) results and Voga et al.'s (2014) results are not directly comparable because of methodological differences and both present potential limitations. As acknowledged by Voga et al. (2014), while the two studies did use the same critical items, the proportion between critical items (i.e., real words) and distractors (i.e., non-words and fillers words) differs significantly: 21 critical items vs 303 filler items for Silva and Clahsen (2008), but the same number of critical items and distractors for Voga et al. (2014). Such a proportion is likely to have an impact on participants' discrimination choices (between words vs non-words) and, possibly, on the developing of participants' expectations about prime-target relations. Moreover, Voga et al. (2014) replicated the original experiment only for the L2 group. Although the priming effect emerges consistently throughout the rich literature on L1 English and can therefore be expected in Silva and Clahsen's (2008) replication, technically, Voga et al. (2014) does not provide any direct between-group comparison. Finally, as none of the studies used an orthographic control condition, the observed effects cannot be distinguished from purely formal ones. Consequently, we cannot be completely sure that such effects are not simply due to the orthographic overlap between the prime and the target. Although for all of the reasons discussed, Voga et al.'s (2014) results need to be considered with caution, they do seem to cast some doubts on the dichotomist view of inflection $v s$ derivation.

A further confirmation of the efficiency of L2 processing mechanisms seems to come from the study conducted by Coughlin and Tremblay (2015) on L2 French (L1 English) which used inflected (e.g., aimons) and orthographic (e.g., aide) primes on the same target (e.g., aime), although in a quite unusual experimental 
design, which combines masked-priming with a naming task. ${ }^{7}$ Their results revealed "full morphological priming in L2 learners, with size of this priming effect increasing with French proficiency. Recall that full priming is defined as the morphological condition being significantly different from the unrelated condition but not significantly different from the identity condition" (Coughlin and Tremblay 2015: 11). Similarly, Foote (2015) found significant priming effects in L2 Spanish with morphologically related prime-target pairs not only with respect the unrelated control condition, but crucially also with respect to the orthographic and semantic conditions. More specifically, Foote investigated both verbal inflection (indicative and subjunctive forms, e.g., cante/CANTA) and nominal inflection (masculine and feminine form: e.g., tonto/TONTA).

Recent results, therefore, seem to indicate that the inflection $v s$ derivation dichotomy posited by some models of morphology is not always confirmed, and that there is no compelling evidence in favor of the postulated impairment in the parsing/decompositional mechanism. On the contrary, more recent results would better fit into models like CxM, which do not advocate a strong and substantial dichotomy between inflection and derivation, but rather abstract schemas which display different properties according to both formal and semantic factors, and which are modulated by quantitative (extra-linguistic) features.

\section{Regular vs Irregular Inflection}

Another critical dimension that has typically been explored in order to verify the relative reliance on computation $v s$ storage in L1 and L2 processing, is the opposition between regular and irregular inflection. We will show that, similarly to what emerged with the dichotomy between inflection and derivation in L2 research, although both results and interpretations are not consistent, the initially suggested strong opposition does not seem to be confirmed substantially. First data come from Neubauer and Clahsen (2009), who contrasted the effect of regular past participles primes to the effect of irregular past participle primes in L2 German (e.g., geordnet/ORDNE 'arrange-(I) arrange' vs. gefahren/FAHRE 'drive(I)' respectively), in a design where both kind of primes had the same formal and semantic overlap with their targets. The patterns of the obtained effects with nonnative speakers indicated partial priming induced by irregular participles, and no priming yielded by regular participles. Therefore, the main L1-L2 differences are found in regular inflection rather than in irregular inflection (or derivation), as is

\footnotetext{
7 "Participants sat in front of a computer screen wearing a head-mounted microphone connected to a digital recorder which audiorecorded them during the entirety of the experiment. Participants were told that they would first see a row of hash signs (\#\#\#\#\#\#), followed by a French word. They were instructed to read the French word aloud as soon as they saw it on the screen and as rapidly as possible. They were told not to correct themselves if they made mistakes" (Coughlin and Tremblay 2015: 9-10).
} 
expected if L2 speakers do not computationally process regularly inflected forms through their morphological structure. On the other hand, partial masked priming effects for irregularly inflected forms and for derived words, would be due to lexical connections. Of course, this kind of interpretation is prone to all the criticisms that we mentioned for the derivation $v s$ inflection opposition.

Clahsen and colleagues' conclusions are brought into question by subsequent results for L2 English obtained by Feldman et al. (2010), who compared the morphological effects produced by regularly inflected past forms (e.g., billed-bill) to the effects of two types of irregular past tense forms (e.g., fell-fall and taughtteach). Interestingly, Feldman and colleagues' study gave the first evidence of a robust facilitation triggered by regularly inflected words in advanced L2 learners, thus falsifying the L2 impairment suggested by Silva and Clahsen (2008) and following studies (such an effect will be confirmed by Voga et al. 2014 and Coughlin and Tremblay 2015). Furthermore, the morphological effects with inflected primes were significant relative not only to the unrelated condition but also relative to the orthographic condition, confirming that what emerges is not a formal side effect but rather a genuinely morphological one. More interesting, no fully reliable difference could be observed between regular and irregular verb types, which clearly suggests that the effects induced by regular and irregular primes cannot be conceived as an all-or-none question, but rather as the result of a complex interplay of different factors (mainly, semantic and formal overlap). In other terms, the similar effects of regular and irregularly inflected primes call into doubt the obligatoriness of the decomposition process in morphological processing. In fact, if only regularly inflected forms are decomposed, and irregular are accessed through lexical connections, different patterns of priming effects should emerge with regular and irregular forms, which is evidently not the case here. The conclusion, thus, is that: "the failure to detect reliable differences in magnitudes of facilitation across regular and irregular verb types poses challenges to the explanatory adequacy of a decompositional vs non-combinatorial association processing dichotomy based on inflectional regularity in either native or non-native speakers of English [...] Collectively, results fail to provide compelling evidence that L1 speakers process regular and irregular verbs by distinct mechanisms, or that L1 and L2 speakers differently engage decompositional and non compositional associative processes" (Feldman et al. 2010: 15).

These first and provisional data coming from L2 research confirm what was found for L1, and has been widely discussed as being problematic for decompositional approaches. However, the implication for L2 processing is quite straightforward: if no reliable difference between regular and irregular emerges with non-native speakers, there is no evidence of a L1/L2 difference rooted in the computation vs storage opposition as claimed in the first studies. These results are definitely more compatible with holistic single mechanism approaches, which, as is the case with CxM, jointly considers formal and semantic overlapping (i.e., shared form and meaning between the prime and the target) and the patterns of similarity among complex words. 


\section{Frequency and Series Effects}

Frequency effects have been traditionally exploited to investigate the storage vs. computation mechanisms with native speakers. Generally, their effects have been observed by means of lexical decision tasks (Burani and Caramazza 1987; Colé et al. 1989; Schreuder et al. 2002; Burani and Thornton 2003) but recently, masked priming experiments have also been conducted that manipulated different prime/target frequency ratios (Voga and Giraudo 2009; Giraudo et al. 2016; Orihuela and Giraudo submitted). As for the L2 learners, only Dal Maso and Giraudo (2014) observed the role of frequency and series size during the processing of derived words, but their outcomes suggest that this domain asks for of further investigation. Specifically, they focused on (semantically transparent) deadjectival nouns ending in -ità and -ezza in L2 Italian, and compared the effects of high frequency primes (e.g., velocità $/$ ELOCE; bellezza/BELLO) and low frequency primes (e.g., brevità/BREVE; contentezza/CONTENTO) in the recognition of their stems, whose frequency was held constant. Results indicated that learners with middle or high proficiency in the L2 are sensitive to both dimensions, as a significant effect was observed only with frequent primes and with the larger series. Interestingly, the fact that only high frequency primes induced a significant effect suggests that the derived prime was accessed as a whole form, whose availability in the mental lexicon was a function of its frequency. In fact, if the prime were parsed and accessed through its stem, we would have observed the same magnitude of effect with both kinds of primes because their stems had comparable frequency. Morphological families are thus not necessarily accessed through their stems, while words belonging to the same family might be connected and activated. The connections within a family would be modulated by usage.

Moreover, primes ending with -ità induced stronger effects than primes ending with $-e z z a$ (which showed only a tendency to significance), indicating that words belonging to larger series (here -ità) are represented according to morphological parameters in the earliest phases of second language acquisition. Series effects of this kind indicate that suffixed words are mentally organized according to abstract schemas, whose strength of representation and activation threshold depends on availability in the input.

\section{Conclusions}

L2 processing is a quite young but lively domain of scientific research, where the still limited results available cannot be easily fitted into a uniform model. Therefore, the aim of the present contribution was not to provide an ultimate model for L2 processing, but rather to suggest alternative views for the most critical aspects emerging from recent research. We tried to show that the initial hypothesis of a substantial difference between native and non-native speakers processing, based on 
a clear-cut separation between storage and computational mechanisms, is not really confirmed by subsequent studies. We discussed psycholinguistic research focusing on morphological processing which are typically exploited in order to disentangle storage $v s$ computation and whole-form $v s$ morpheme-based representation in the mental lexicon, i.e. inflection vs. derivation, regular vs. irregular inflection, and frequency and series effects. Recent L2 results do not support a strong opposition between the processing of inflection and derivation or between the processing of regular and irregular inflected forms. Instead, they suggest that a model which captures the formal and semantic similarity among complex words and represents them in terms of abstract constructions is better suited to account for the results obtained so far. Moreover, the observed family and series effects seem to indicate that the processing of complex words crucially depends on the strength of their paradigmatic relationships, i.e., their connections with words belonging to the same family (stem and derived forms) or to the same series (forms constructed with the same affix). In such a model, morphological processing does not necessarily imply the parsing of complex words into its morphological constituents but can be conceived as the reciprocal activation of connected forms.

\section{References}

Abutalebi, J., and D.W. Green. 2008. Control mechanisms in bilingual language production: Neural evidence from language switching studies. Language and Cognitive Processes 23: 557-582.

Anderson, S.R. 1982. Where's morphology? Linguistic Inquiry 13: 571-612.

Basnight-Brown, D., H. Chen, H. Shu, A. Kostić, and L.B. Feldman. 2007. Monolingual and bilingual recognition of regular and irregular English verbs: Does sensitivity to word form vary with language experience? Journal of Memory and Language 57: 65-80.

Boudelaa, S., and W.D. Marslen-Wilson. 2011. Productivity and priming: Morphemic decomposition in Arabic. Language \& Cognitive Processes 26: 624-652.

- 1996. Inherent versus contextual inflection and the split morphology hypothesis. In Yearbook of morphology 1995, ed. G. Booij and J. van Marle, 1-16. Dordrecht: Kluwer. . 2010. Construction morphology. Oxford: Oxford University Press.

Bosch, S., and H. Clahsen. 2016. Accessing morphosyntax in L1 and L2 word recognition: A priming study of inflected German adjectives. The Mental Lexicon 11: 26-54.

Burani, C., and A. Caramazza. 1987. Representation and processing of derived words. Language and Cognitive Processes 2: 217-227.

Burani, C., and A.M. Thornton. 2003. The interplay of root, suffix and whole-word frequency in processing derived words. In Morphological structure in language processing, ed. R.H. Baayen and R. Schreuder, 157-208. Berlin: Mouton de Gruyter.

Bybee, J.L. 1985. Morphology: A study of the relation between meaning and form. Amsterdam: John Benjamins.

Caramazza, A., A. Laudanna, and C. Romani. 1988. Lexical access and inflectional morphology. Cognition 28: 297-332.

Chen, L., H. Shu, J. Liu Zhao, and P. Li. 2007. ERP signatures of subject-verb agreement in L2 learning. Bilingualism: Language and Cognition 10: 161-174.

Clahsen, H., and C. Felser. 2006. How native-like is non-native language processing? Trends in Cognitive Science 10: 564-570. 
Clahsen, H., and C. Felser. 2017. Some notes on the shallow structure hypothesis. Studies in Second Language Acquisition. Advance online publication. https://doi.org/10.1017/S0272263117000250.

Clahsen, H., and Y. Ikemoto. 2012. The mental representation of derived words: An experimental study of -sa and -mi nominals in Japanese. The Mental Lexicon 7: 147-182.

Clahsen, H., and K. Neubauer. 2010. Morphology, frequency, and the processing of derived words in native and non-native speakers. Lingua 120: 2627-2637.

Clahsen, H., I. Sonnensthul, and J.P. Blevins. 2003. Derivational morphology in the mental lexicon: A dual mechanism account. In Morphological structure in language processing, ed. R.H. Baayen and R. Schreuder, 125-155. Berlin/New York: Mouton-De Gruyter.

Clahsen, H., C. Felser, K. Neubauer, M. Sato, and R. Silva. 2010. Morphological structure in native and non-native language processing. Language Learning 60: 21-43.

Colé, P., C. Beauvillain, and J. Segui. 1989. On the representation and processing of prefixed and suffixed derived words: A differential frequency effect. Journal of Memory and Language 28: $1-13$.

Coughlin, C., and A. Tremblay. 2015. Morphological decomposition in native and non-native French speakers. Bilingualism: Language and Cognition 18: 1-19.

Dal Maso, S., and H. Giraudo. 2014. Masked morphological priming in Italian L2: Evidence from masked priming. Lingvisticae Investigationes 37: 322-337.

Dal Maso, S., and H. Giraudo. submitted. On the interplay of family and series effects in visual word recognition. Morphology, Special Issue: Paradigms in Word-formation.

Diependaele, K., J.A. Duñabeitia, J. Morris, and E. Keuleers. 2011. Fast morphological effects in first and second language word recognition. Journal of Memory and Language 64: 344-358.

Diependaele, K., J. Grainger, and D. Sandra. 2012. Derivational morphology and skilled reading: An empirical overview. In The Cambridge handbook of psycholinguistics, ed. M. Spivey, K. McRae, and M. Joanisse, 311-332. Cambridge: Cambridge University Press.

Ding, G., D. Peng, and M. Taft. 2004. The nature of the mental representation of radicals in Chinese: A priming study. Journal of Experimental Psychology: Learning, Memory, and Cognition 30: 530-539.

Domínguez, A., J. Segui, and F. Cuetos. 2002. The time-course of inflectional morphological priming. Linguistics 40: 235-259.

- 1989. Prototypical differences between inflection and derivation. Zeitschrift für Phonetik, Sprachwissenschaft und Kommunikationsforschung 42: 3-10.

Drews, E., and P. Zwitserlood. 1995. Morphological and orthographic similarity in visual word recognition. Journal of Experimental Psychology: Human Perception and Performance 21: 1098-1116.

Ellis, N.C. 2005. At the interface: Dynamic interactions of explicit and implicit language knowledge. Studies in Second Language Acquisition 27: 305-352.

Feldman, L.B. 2000. Are morphological effects distinguishable from the effects of shared meaning and shared form? Journal of Experimental Psychology: Learning, Memory, and Cognition 26: 1431-1444.

Feldman L.B., D. Barac-Cikoja, and A. Kostić. 2000. Semantic aspects of morphological processing: Transparency effects in Serbian. Paper presented at the Psychonomic Society, November, New Orleans, LA.

Feldman, L.B., A. Kostić, D.M. Basnight-Brown, D.F. Đurđević, and M.J. Pastizzo. 2010. Morphological facilitation for regular and irregular verb formations in native and non-native speakers: Little evidence for two distinct mechanisms. Journal of Bilingualism: Language and Cognition 13: 119-135.

Foote, R. 2015. The storage and processing of morphologically complex words in L2 Spanish. Studies in Second Language Acquisition 37: 1-33.

Forster, K.I. 1998. The pros and cons of masked priming. Journal of Psycholinguistic Research 27: 203-233.

Forster, K.I., and C. Davis. 1984. Repetition priming and frequency attenuation in lexical access. Journal of Experimental Psychology: Learning, Memory, and Cognition 10: 680-698. 
Fowler, C.A., S.E. Napps, and L.B. Feldman. 1985. Relations among regular and irregular morphologically related words in the lexicon as revealed by repetition priming. Memory and Cognition 13: 241-255.

Giraudo, H., and S. Dal Maso. 2016a. Suffix perceptual salience in masked morphological priming. Lingue e Linguaggio 15: 85-103.

. 2016b. The salience of complex words and their parts: Which comes first? Frontiers in Psychology 7: 1-8.

Giraudo, H., and J. Grainger. 2000. Effects of prime word frequency and cumulative root frequency in masked morphological priming. Language and Cognitive Processes 15: 421-444.

. 2001. Priming complex words: Evidence for supralexical representation of morphology. Psychonomic Bulletin \& Review 8: 127-131.

Giraudo, H., and M. Voga. 2007. Lexeme-based model vs. morpheme-based model from psycholinguistic perspectives. In Selected Proceedings of the 5th Décembrettes: Morphology in Toulouse, ed. F. Montermini, G. Boyé, and N. Hathout, 108-114. Somerville: Cascadilla Proceedings Project.

2014. Measuring morphology: The tip of the iceberg? A retrospective on 10 years of morphological processing. Carnets de Grammaire 22: 136-167.

Giraudo, H., S. Dal Maso, and S. Piccinin. 2016. The role of stem frequency in morphological processing. In On-line proceedings of the 10th Mediterranean Morphology Meeting (MMM10), Quo vadis morphology? Grammar, Cognition and Computation, 64-72.

Gonnerman, L.M., M.S. Seidenberg, and E.S. Andersen. 2007. Graded semantic and phonological similarity effects in priming: Evidence for a distributed connectionist approach to morphology. Journal of Experimental Psychology: General 136: 323-345.

Gor, K., and S. Cook. 2010. Non-native processing of verbal morphology: In search of regularity. Language Learning 60 (1): 88-126.

Gor, K., and S. Jackson. 2013. Morphological decomposition and lexical access in a native and second language: A nesting doll effect. Language and Cognitive Processes 28: 1065-1091.

Henderson, L. 1985. Towards a psychology of morphemes. In Progress in the psychology of language, ed. A.W. Ellis, vol. I, 15-68. London: Lawrence Erlbaum.

Heyer, V., and H. Clahsen. 2015. Late bilinguals see a scan in scanner AND in scandal: Dissecting formal overlap from morphological priming in the processing of derived words. Bilingualism: Language and Cognition 18: 543-550.

Jacob, G., E. Fleischhauer, and H. Clahsen. 2013. Allomorphy and affixation in morphological processing: A cross-modal priming study with late bilinguals. Bilingualism: Language and Cognition 16: 924-933.

Jacob, G., V. Heyer, and J. Veríssimo. 2017. Aiming at the same target: A masked priming study directly comparing derivation and inflection in the second language. International Journal of Bilingualism. https://doi.org/10.1177/1367006916688333.

Kim, S.Y., M. Wang, and M. Taft. 2015. Morphological decomposition in the recognition of prefixed and suffixed words: Evidence from Korean. Scientific Studies of Reading 19: 183-203.

Kirkici, B., and H. Clahsen. 2013. Inflection and derivation in native and non-native language processing: Masked priming experiments on Turkish. Bilingualism: Language and Cognition 16: 776-794.

Kroll, J., and E. Stewart. 1994. Category interference in translation and picture naming: Evidence for asymmetric connections between bilingual memory representations. Journal of Memory and Language 33: 149-174.

Langacker, R.W. 1987. Foundations of cognitive grammar: Vol. 1. Theoretical prerequisites. Stanford: Stanford University Press.

MacWhinney, B. 2011. Language development. In Developmental science: An advanced textbook, ed. M. Bornstein and M. Lamb, 389-424. New York: Psychology Press.

Marslen-Wilson, W.D., and L.K. Tyler. 1997. Dissociating types of mental computation. Nature 387: 592-594. 
McDonald, J.L. 2006. Beyond the critical period: Processing-based explanations for poor grammaticality judgment performance by late second language learners. Journal of Memory and Language 55: 381-401.

Morris, J., J. Grainger, and P.J. Holcomb. 2013. Tracking the consequences of morphoorthographic decomposition using ERPs. Brain Research 1529: 92-104.

Neubauer, K., and H. Clahsen. 2009. Decomposition of inflected words in a second language: An experimental study of German participles. Studies in Second Language Acquisition 31: 403-435.

Nikolova, R., and G. Jarema. 2002. Interaction of morphological structure and prefix transparency in the processing of Bulgarian aspectual verb forms. Brain and Language 81: 649-665.

Orihuela, K., and H. Giraudo. submitted. Reversing the surface frequencies of prime-target morphologically related pairs: Implications for the decompositional and holistic approaches of lexical access.

Pastizzo, M.J., and L.B. Feldman. 2002. Discrepancies between orthographic and unrelated baselines in masked priming undermine a decompositional account of morphological facilitation. Journal of Experimental Psychology: Learning, Memory and Cognition 28: 244-249.

Perani, D., and J. Abutalebi. 2005. The neural basis of first and second language processing. Current Opinion in Neurobiology 15: 202-206.

Perlmutter, D.M. 1988. The split morphology hypothesis: Evidence from Yiddish. In Theoretical morphology, ed. M. Hammond and M. Noonan, 79-100. San Diego: Academic.

Pinker, S. 1991. Rules of language. Science 253: 530-535.

Pinker, S., and A. Prince. 1988. On language and connectionism: Analysis of a parallel distributed model of language acquisition. Cognition 28: 73-193.

Plank, F. 1994. Inflection and derivation. In Encyclopedia of language and linguistics, ed. R.E. Asher, vol. 3, 1671-1678. Oxford: Pergamon Press.

Portin, M., M. Lehtonen, and M. Laine. 2007. Processing of inflected nouns in late bilinguals. Applied Psycholinguistics 28: 135-156.

Rastle, K., and M.H. Davis. 2008. Morphological decomposition based on the analysis of orthography. Language and Cognitive Processes 23: 942-971.

Raveh, M., and J. Rueckl. 2000. Equivalent effects of inflected and derived primes: Long-term morphological priming in fragment completion and lexical decision. Journal or Memory and Language 42: 103-119.

Sabourin, L., and M. Haverkort. 2003. Neural substrates of representation and processing of a second language. In The lexicon-syntax interface in second language acquisition, ed. R. van Hout, A. Hulk, F. Kuiken, and R. Towell, 175-195. Amsterdam: Benjamins.

Schreuder, R., and R.H. Baayen. 1995. Modeling morphological processing. In Morphological aspects of language processing, ed. L.B. Feldman, 131-154. Hove: Erlbaum.

Sereno, J., and A. Jongman. 1997. Processing of English inflectional morphology. Memory and Cognition 25: 425-437.

Silva, R., and H. Clahsen. 2008. Morphologically complex words in L1 and L2 processing: Evidence from masked priming experiments in English. Bilingualism: Language and Cognition 11: $245-260$.

Stanners, R.F., J.J. Neiser, W.P. Hernon, and R. Hall. 1979. Memory representation for morphologically related words. Journal of Verbal Learning and Verbal Behavior 8: 399-412.

. 1985. The lexical account of word naming considered further. Behavioral and Brain Sciences 8: 689-740.

- 1994. Interactive activation as a framework for understanding morphological processing. Language and Cognitive Processes 9: 271-294.

Taft, M., and K.I. Forster. 1975. Lexical storage and retrieval of prefixed words. Journal of Verbal Learning and Verbal Behavior 14: 638-647.

Ullman, M. 2004. Contributions of memory circuits to language: The declarative/procedural model. Cognition 92: 231-270.

. 2006. The declarative/procedural model and the shallow-structure hypothesis. Journal of Applied Psycholinguistics 27: 97-105. 
Voga, M., and J. Grainger. 2004. Masked morphological priming with varying levels of form overlap: Evidence from Greek verbs. Current Psychology Letters: Behaviour, Brain \& Cognition 13 (2): $1-10$.

Voga, M. 2005. Amorçage masqué cognate inter-alphabet: rôle des facteurs morphologique et phonologique. Revue d'Intelligence Artificielle 19: 407-426.

Voga, M., A. Anastassiadis-Syméonidis, and H. Giraudo. 2014. Does morphology play a role in L2 processing? Two masked priming experiments with Greek speakers of ESL. Lingvisticae Investigationes 37: 338-352. 